\title{
A STUDY TO ASSESS THE KNOWLEDGE, ATTITUDE AND PRACTICE REGARDING UPPER RESPIRATORY TRACT INFECTION AMONG MOTHERS OF UNDER FIVE YEAR'S AGE CHILDREN AT ANMOL CHILD HEALTH \& GENERAL HOSPITAL DAUSA, RAJASTHAN
}

\author{
Mr. SHIV KUMAR SHARMA \\ Associate Professor \\ Mahatma Gandhi University of Medical Sciences \& Technology, Jaipur
}

Corresponding Email: shivsharma@mgumst.org

\begin{abstract}
Introduction: "The nation walks on the feet of little children. Children are the wealth of tomorrow. Take care of them if you wise to have a strong India."

Good health is the cornerstones for survival, and development for current and succeeding generations. Healthy child perform better in school, grow into healthy adults and in turn give their children a better start in life.
\end{abstract}

Material \& Methods: In this study Descriptive research design was used. Total 100 mothers of under five year age children were selected by convenient sampling technique from whoever attending pediatric ward in anmol child hospital Dausa.

Result: $47.4 \%$ of the mothers are having knowledge on upper respiratory tract infection. $53.7 \%$ of the mother having positive attitude on upper respiratory tract infection.

Conclusion: Concluded that the level of knowledge, attitude, and practice regarding upper respiratory tract infection among mothers of under five year age children was find adequate.

KEY WORDS:-Mothers of under five, knowledge, attitude, practice, URI

\section{INTRODUCTION:}

UNICEF, (2006) Good health is the cornerstone for survival, and development for current and succeeding generations. Healthy child perform better in school, grow into healthy adults and in turn give their children a better start in life. Physical growth and mental development of children depends upon the interaction between nature and health. Children must receive a well balanced diet and optimum health to enable them to achieve their full genetic potential. ${ }^{1}$

Lippincott (2001) Respiratory diseases are the disease related to the gaseous exchange. That is the disorders in the nose, nasopharynx, larynx, trachea, bronchi and lungs. There are acute and chronic respiratory diseases. Acute respiratory diseases are the diseases, which is a rapid onset with severe symptoms and sharp course. Chronic respiratory diseases 
are the diseases which persisting for a long time. $^{2}$

Denno DM, (1994) acute respiratory infections (ARI) are a major cause of pediatric mortality and morbidity, particularly when associated with delays in treatment.

Saini NK, Gaur DR (1992) acute respiratory tract infections (ARI) are very common in India, with 30-60 million episodes of pneumonia and severe pneumonia occurring annually in under fives. They are important causes of child morbidity and mortality, accounting in India for $14.3 \%$ of infant mortality and $15.9 \%$ of mortality among $1-5$ year olds. The majority of these deaths could, however, be prevented if mothers knew the signs and symptoms associated with infections so that timely referrals could be made. Mothers also need to provide supportive care to these children during illness.

\section{OBJECTIVES:-}

- To find out the knowledge, attitude and practice of the mothers regarding the Upper respiratory tract infection.

- To determine the relationship between the knowledge and attitude of mothers regarding the Upper respiratory tract infection

- To determine the relationship between the attitude and practice of mothers regarding the Upper respiratory tract infection.

- To determine the relationship between the knowledge and practice of mothers regarding the Upper respiratory tract infection.

- To find out the association between the knowledge and demographic variables (Age, Educational states, Area, Income,) of the mothers regarding the Upper respiratory tract infection

- To find out the association between the attitude and demographic variables (Age, Educational states, Area, Income,) of the mothers regarding the Upper respiratory tract infection

- To find out the association between the practice and demographic variables (Age, Educational states, Area, Income,) of the mothers regarding the Upper respiratory tract infection.

\section{HYPOTHESES:-}

$\mathrm{H}_{1^{-}}$There is a significant relationship between knowledge and Attitude of Mothers Regarding Upper respiratory tract Infection.

$\mathrm{H}_{2^{-}}$There is a significant relationship between attitude and Practice of mothers regarding Upper respiratory tract infection

$\mathrm{H}_{3}$ - There is a significant relationship between knowledge and Practice of 
mothers regarding Upper respiratory tract infection.

$\mathrm{H}_{4}-$ There is a significant association between knowledge and Demographic variables (Age, Educational states, Area, Income,) of the mothers regarding the Upper respiratory tract infection.

$\mathrm{H}_{5^{-}}$There is a significant association between Attitude and Demographic variables (Age, Educational states, Area, Income,) of the mothers regarding the Upper respiratory tract infection.

$\mathrm{H}_{6^{-}}$There is a significant association between Practice and Demographic variables (Age, Educational states, Area, Income,) of the mothers regarding the Upper respiratory tract infection

\section{CONCEPTUAL FRAME WORK:-}

The Conceptual framework for the study is based on health belief model. The model was developed by Rosen Stock's \& Beeker.

\section{MATERIAL \& METHODS}

RESEARCH APPROACH:-The research approach adopted for this research study is a descriptive approach. This approach helps to understand the effect of independent variables on the dependent variables so the above mentioned research approach is suitable for the study.
RESEARCH DESIGN:-For this study the research design chosen is a Descriptive design. The design was used for assessing the knowledge, attitude and practice regarding Upper respiratory tract infection among mother of under five year's age children.

\section{VARIABLES:-}

INDEPENDENT VARIABLES:-

Mothers of under five year's age children

\section{DEPENDENT}

VARIABLES:-

Knowledge ,attitude and practice regarding Upper respiratory tract infection SETTING OF THE STUDY: The present study was conducted in the Anmol child health \& general hospital Dausa, Rajasthan. It is multi specialty hospital, and patients are drawn from all around Dausa district. In addition to the economic condition of the patient the treatment will be charge. It has 500 beds out of these 80 beds are meant for Pediatric medical ward $50 \%$ beds are equipped with patients with URI.

TARGET POPULATION:- The target population of the present study includes the mothers who are coming in the pediatric OPD at Anmol child health \& general hospital Dausa, Rajasthan.

SAMPLE: - mothers of under five years age children who ever attending pediatric OPD at Anmol child health \& general hospital Dausa, Rajasthan 
SAMPLE SIZE: - The sample used for the study was 100 mothers of under five years age children

SAMPLING TECHNIQUE: - In this study, the convenient sampling technique was utilized for the selection of the subjects. A sample of 100 mothers of under five years age children were selected for the study in anmol child health \& general hospital, Dausa.

CRITERIA FOR THE SELECTION OF THE SAMPLE:-

\section{DEVELOPMENT OF THE}

INSTRUMENT:-

The researcher has prepared the Structured interview schedule to assess the Knowledge, attitude and practice regarding Upper respiratory tract infection among mother of under five year's age children.

\section{STEPS IN THE CONSTRUCTION OF}

\section{THE INSTRUMENT:-}

The following steps were carried out in the preparation of the instrument.

1. Related literature was reviewed in preparing of the instrument.

2. Guidance and consultation of the Nursing experts and medical experts were taken for the construction of instrument.

\section{DESCRIPTION OF THE}

INSTRUMENT:-The instrument was organized into two sections:-
Section I - Socio-demographic variables of the mother of under five year's age children.

Section II- the structured interview schedule to assess the knowledge, attitude and Practice regarding Upper respiratory tract infection among mother of under five year's age children.

\section{RESULTS:}

$47.4 \%$ of the mothers are having Knowledge on Upper respiratory tract infection. Or we can say out of 20 questions they are able to answer on an average 9 questions of respiratory tract infection.

$53.7 \%$ of the mothers are having positive attitude on Upper respiratory tract infection. Or we can say out of 30 score they are able to score on an average 16.12 of respiratory tract infection questions $54.7 \%$ of the mothers are having positive practice on Upper respiratory tract infection. Or we can say out of 10 questions they are able to answer only 5 questions of respiratory tract infection questions

The findings of the study revealed that determine the relationship between the knowledge and attitude of mothers regarding the Upper respiratory tract infection was significant by the Karl Pearson $\mathrm{r}=0.42$ and $\mathrm{p}=0.001$ 
The findings of the study revealed that determine the relationship between the attitude and practice of mothers regarding the Upper respiratory tract infection was significant by the Karl Pearson $r=0.28$ and $\mathrm{p}=0.001$.

The findings of the study revealed that determine the relationship between the knowledge and practice of mothers regarding the Upper respiratory tract infection was significant by the Karl Pearson $r=0.44$ and $p=0.001$

The findings of the study revealed that a significant association between the knowledge and demographic variables (Age, Educational states, Area, Income,) of the mothers regarding the Upper respiratory tract infection the level of knowledge is following

- In mother age was $\chi^{2}=4.78$ and $p=$ 0.02 .

- Educational status was $\chi^{2}=10.71$ and $p=0.01$.

- $\quad$ Residential area was $\chi^{2}=11.81$ and $p=0.001$

The findings of the study revealed that a significant association between the attitude and demographic variables (Age, Educational states, Area, Income,) of the mothers regarding the Upper respiratory tract infection the level of attitude is following
- In child age was $\chi^{2}=7.22$ and $p=$ 0.03 .

- Occupational status was $\chi^{2}=9.14$ and $p=0.02$.

- $\quad$ Type offamily was $\chi^{2}=3.84$ and $p=$ 0.05 .

The findings of the study revealed that a significant association between the practice and demographic variables (Age, Educational states, Area, Income,) of the mothers regarding the Upper respiratory tract infection the level of practice is following

- Education status was $\chi^{2}=10.47$ and $p=0.01$.

- $\quad$ Type of house was $\chi^{2}=6.93$ and $p=$ 0.03

\section{INTERPRETATION AND}

\section{CONCLUSION:-}

The findings of this study support the need for pediatric nurses to conduct health education programme, to increase the knowledge, attitude, and practice of the mother regarding upper respiratory tract infection, Thus for the future there is a need to improve their knowledge, attitude, and practice by conducting the health awareness programme.

01. A large sample can be included for the study in an out-patient paediatric department in a hospital.

02. A study can be conducted in the rural and urban primary health center. 
03. Study can be conducted at remote area.

04. A study can be conducted to identify various factors affecting respiratory function of under five children.

05. Educational programmes can be designed to create awareness among parents.

\section{REFERENCES:}

1. Lippincott2001, manual nursing and practice $7^{\text {th }}$ edition , Lippincott newyork.

2. Gupta Neeru jain Sk, Ratnesh,Chawla Uma, Hossain Shah,Venkatesh S an evaluation of diarrheal diseases and acute respiratory infection control programmes in a Delhi slum,year 2007 Volume 74 Issue 5 page 471-76

3. Khallaf N, Pio A. A national programme for the control of acute respiratory infections World Health Forum. 1998;18(3-4):339-44

4. Denno DM, Bentsi-Enchil A, Mock Cn, Adelson JW. Maternal Knowledge, Attitude and practice regarding childhood acute respiratory infections inKumasi,Ghana.AnnTropPaediatr.199 4:14(4):293-301

5. Oviawe O,Oviawe N. Acute respiratory infection in an infant. Niger J Pediatr.1998 Africa Jan;20(1):21-3
6. Aten Primaria 1998 Mar 31;19(5):2636.Related Articles, Links[Acute respiratory infections (ARI) in the $0-14$ years of age group during the winter period]

7. Alves RC, Veríssimo Mde L Knowledge and practices of university day care center workers relative to acute respiratory infections in childhood: Rev Esc Enferm USP. 2006 Mar;40(1):78-85.

8. Aung T, Tun KM, Thinn K, Thein AA Knowledge, attitudes and practices of mothers on childhood acute respiratory infections (ARI). Southeast Asian J Trop Med Public Health. 1998 Yangon, Myanmar Sep;25(3):590-3

9. Bener A Al- Khal A. Knowledge, attitude and practice towards SARS. J R Soc Health. 2004 Jul;124(4):167-70

10. Blazquez Hernanz MC, Llamas Sandino A, Blázquez Hernanz LM. Acute respiratory infections (ARI) in the $0-14$ years of age group during the winter period Aten Primaria. 1998 Madrid Mar 31;19(5):263-6 